\title{
Efficacy and Safety of rituximab in children with difficult-to-treat nephrotic syndrome; a systematic review
}

\author{
Anoush Azarfar $^{\circledR}$, Yalda Ravanshad ${ }^{2,3^{*}}{ }^{\circledR}$, Hassan Mehrad-Majd ${ }^{2}$, Shapour Badiei Aval ${ }^{4}$, Sanaz \\ Nastarani ${ }^{1}$, Maryam Emadzadeh ${ }^{2}$, Mahmood Reza Khazaei ${ }^{5}$, Mojtaba Fazel ${ }^{6}$, Behnam Azimi ${ }^{1}$ \\ ${ }^{1}$ Department of Pediatrics, Mashhad University of Medical Sciences, Mashhad, Iran \\ ${ }^{2}$ Clinical Research Unit, Mashhad University of Medical Sciences, Mashhad, Iran \\ ${ }^{3}$ Department of Community Medicine, Mashhad Branch, Islamic Azad University, Mashhad, Iran \\ ${ }^{4}$ Department of Acupuncture, Faculty of Medicine, Mashhad University of Medical Sciences, Mashhad, Iran \\ ${ }^{5}$ Department of Pediatrics, Mashhad Medical Sciences Branch, Islamic Azad University, Mashhad, Iran \\ ${ }^{6}$ Valiasr Hospital, Imam Khomeini Complex, Tehran University of Medical Sciences, Tehran, Iran
}

\section{A R T I C L E I N F O}

Article Type:

Review

\section{Article History:}

Received: October 2017

Accepted: 18 February 2018

Published online: 8 March 2018

\section{Keywords:}

Rituximab,

Nephrotic syndrome

Children

Treatment

Proteinuria

Hypoalbuminemia

Hypercoagulability

Dyslipidemia

\begin{abstract}
A B S T R A C T
To date, several studies have been done on efficacy and safety of drugs in children with refractory nephrotic syndrome (NS). Rituximab (RTX) might be a hopeful treatment for this syndrome. However, the long-term effects and cost-effectiveness of RTX treatment were not fully assessed. This study aims to do a systematic review about the efficacy and safety of RTX in children with difficult-to-treat NS. For this research, an electronic literature search was conducted to identify appropriate investigations. The search term was ("nephrotic syndrome" or "minimal change disease" or "focal segmental glomerulosclerosis" or membranous) and ("rituximab" or "CD20"). We included all randomized trials and observational studies about using RTX in children with difficult-to-treat NS. Two independent reviewers extracted data from the papers according to the selection criteria. Eligible studies were included in this systematic review. The literature search and reference mining yielded 919 potential relevant papers. We removed 340 articles because of duplication. We also excluded 513 papers after reviewing the titles and abstracts. Finally, 17 studies were included in the systematic review. Efficacy of RTX in children with NS in most of the studies was assessed with relapse-free survival or complete remission rates. Acknowledging the limitations of the study due to the size and nature of the studies included, our systematic review shows that RTX was effective in the treatment of refractory NS in children, and it could reduce the use of steroid and immunosuppressants. However, further large randomized trials are suggested.
\end{abstract}

Implication for health policy/practice/research/medical education:

RTX was effective in the treatment of refractory NS in children, and it could reduce the use of steroid and immunosuppressants. However, further large randomized trials are suggested.

Please cite this paper as: Azarfar A, Ravanshad Y, Mehrad-Majd H, Badiei Aval S, Nastarani S, Emadzadeh M, et al. Efficacy and Safety of rituximab in children with difficult-to-treat nephrotic syndrome; a systematic review. J Renal Inj Prev. 2018;7(4):307313. doi: 10.15171 /jrip.2018.67.

\section{Introduction}

Nephrotic syndrome (NS) is a complication diagnosed by heavy proteinuria, hypoalbuminemia (serum albumin $<2.5 \mathrm{~g} / \mathrm{dL}$ ), often associated with hypercoagulability and dyslipidemia. According to the NS clinical guidelines, for the management of children who develop frequentlyrelapsing NS (FRNS) or steroid-dependent NS (SDNS), a low-dose alternate day steroid regimen, as the first-line treatment, is prescribed (1). Long-term glucocorticoid use in FRNS/SDNS patients leads to reduced bone mineral density, hypertension, increased infection risks, comorbidities such as cushingoid habitus, growth retardation, striae and acne, cataracts, pseudotumor cerebri, impaired glucose tolerance and hypercholesterolemia (2). Approximately $20 \%$ of children do not respond completely and have steroid-resistant NS (SRNS), and $80 \%-90 \%$ of children with steroid-sensitive NS (SSNS) experience relapses. Among these relapsing children, 50\% develop 
SDNS (3). Refractory nephrotic refers to patients with FRNS, SDNS, and SRNS which are difficult to be controlled by variable immunosuppressants (4). Rituximab (RTX) might be a hopeful treatment for refractory NS in children, but the long-term effects and cost-effectiveness of RTX treatment have not been fully assessed (3). Several studies have suggested RTX as a proper drug for the treatment of children with FRNS/SDNS (5-8). This study aims to have a systematic review to identify the efficacy and safety of RTX in children with difficult-to-treat NS.

\section{Methods}

We searched Embase, DOAJ (Directory of open access journals), PubMed, the Cochrane Library, Science Direct, Scopus, and Web of Science (updated up to July 2017). Search term was ("nephrotic syndrome" or "minimal change disease" or "focal segmental glomerulosclerosis" or membranous) and ("rituximab" or "CD20"). We scanned bibliographies in relevant papers and conference proceedings. Studies by the same author were checked for possible overlapping participant groups. If the study was reported as duplicate, only the most recent or complete study was comprised. The following selection criteria were applied; we included all randomized trials and observational studies about using RTX in children with difficult-to-treat NS.

\section{Data extraction and quality assessment}

Two independent reviewers extracted data from the papers according to the selection criteria. Disagreements were resolved by discussion between two reviewers considering the opinion of a third reviewer. The following information was abstracted from each contained investigation; first author and year of publication, design of investigation, sample size, mean age of individuals, intervention regime, follow-up duration, and outcome measures for each group. All the analysis were based on previously published investigations. Hence, no ethical approval or patient consent was required.

Results

Search results and characteristics

The literature search and reference mining yielded 919 potential relevant papers. We removed 340 papers because of duplicate publication. We also excluded 513 papers after reviewing the titles and abstracts while they were books, book sections, and review papers. Thus, they were not relevant. Then, we reviewed full-text of selected articles and removed 49 studies because the topics were not relevant to the subject. Finally, 17 investigations were included in the systematic review (4-20). The flow diagram of study selection is shown in Figure 1. Characteristics and the details of the studies are illustrated in Table 1.

\section{Outcome}

The summary of outcomes of our study is provided in Table 2. Efficacy of RTX in children with NS in most of the studies was assessed with relapse-free survival or complete remission rates. In a study (5), reduction of median yearly number of relapses with use of RTX was reported (5). Some of the studies reported biochemical indicators such as proteinuria (14).

\section{Discussion}

Almost all studies showed that RTX was effective in the treatment of refractory NS in children, and it could

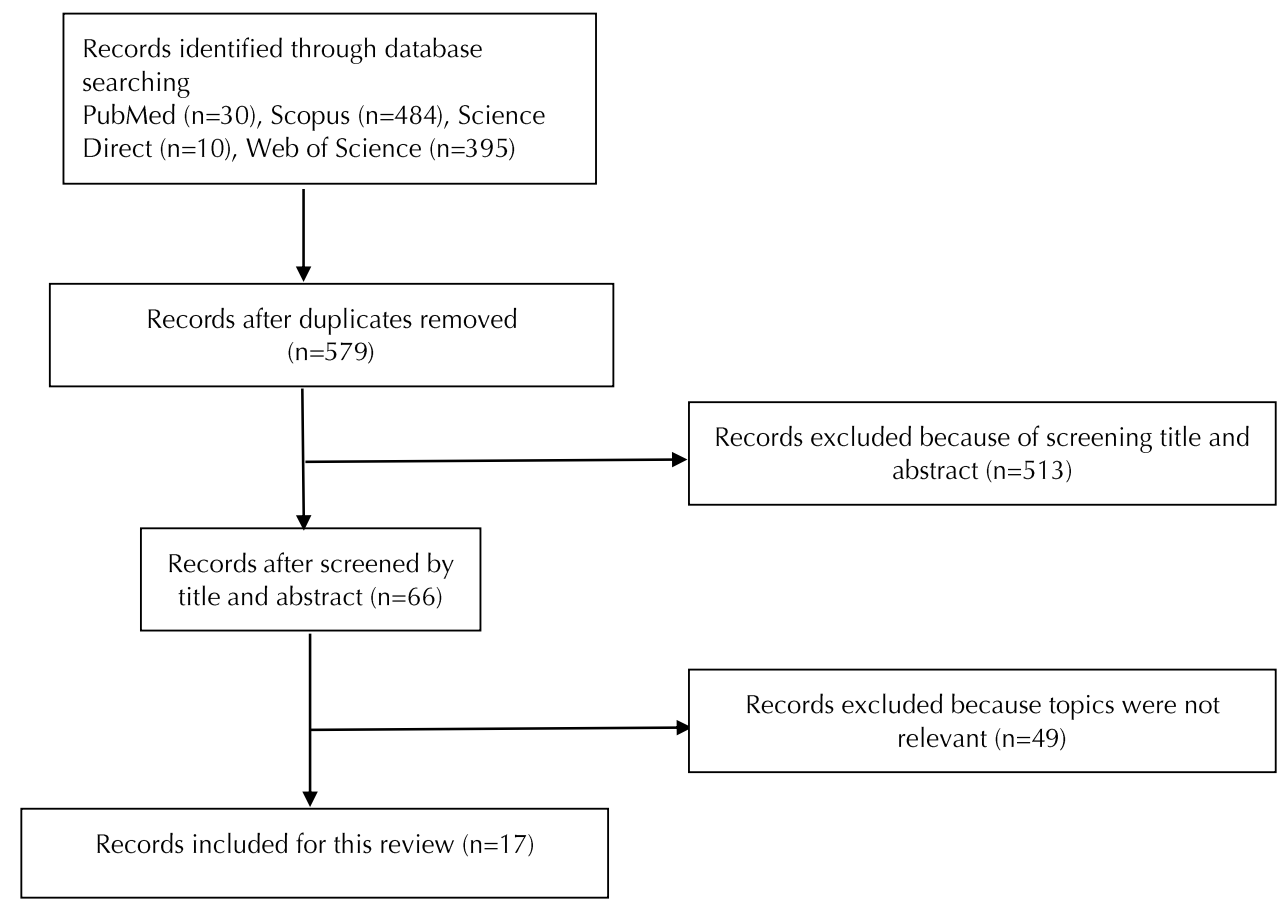

Figure 1. Flow-chart of study selection process. 
Table 1. General characteristics of trials included in this systematic review

\begin{tabular}{|c|c|c|c|c|c|c|c|c|c|c|c|c|}
\hline \multirow{2}{*}{ Reference } & \multirow{2}{*}{ Name } & \multirow{2}{*}{ Year } & \multirow{2}{*}{ Country } & \multirow{2}{*}{ Study design } & \multicolumn{2}{|c|}{ Group } & \multicolumn{2}{|c|}{ Frequency } & \multirow{2}{*}{\multicolumn{2}{|c|}{ Age (Year) }} & \multicolumn{2}{|c|}{ Sex (Male) } \\
\hline & & & & & Case & Control & Case & Control & & & Case & Control \\
\hline 4 & Van Horebeek, I. & 2017 & Belgium & Retrospective & \multicolumn{2}{|c|}{ RTX } & \multicolumn{2}{|c|}{9} & \multicolumn{2}{|c|}{16.08} & \multicolumn{2}{|c|}{ NR } \\
\hline 5 & Webb, $\mathrm{H}$. & 2016 & UK & Retrospective & RTX & Cyclophosphamide & 8 & 59 & Case $=7.5$ & Cont $=6$ & $87 \%$ & $66 \%$ \\
\hline 6 & Niu, X. L. & 2016 & China & Before-after & \multicolumn{2}{|c|}{ RTX } & \multicolumn{2}{|c|}{19} & \multicolumn{2}{|c|}{8.21} & \multicolumn{2}{|c|}{10} \\
\hline 7 & Suyama, K. & 2016 & Japan & Before-after & \multicolumn{2}{|c|}{ RTX, low-dose cyclosporine } & \multicolumn{2}{|c|}{5} & \multicolumn{2}{|c|}{13.9} & \multicolumn{2}{|c|}{3} \\
\hline 8 & Kamei, K. & 2016 & Japan & Retrospective & \multicolumn{2}{|c|}{ RTX } & \multicolumn{2}{|c|}{114} & & & \multicolumn{2}{|c|}{76} \\
\hline 10 & Colucci, M & 2016 & Italy & Retrospective & \multicolumn{2}{|c|}{ RTX } & \multicolumn{2}{|c|}{28} & \multicolumn{2}{|c|}{13.68} & $\begin{array}{c}18 \\
(64 . \%)\end{array}$ & \\
\hline 11 & Chan, C. Y. & 2016 & Singapore & Retrospective & \multicolumn{2}{|c|}{ RTX } & & 22 & \multicolumn{2}{|c|}{14.4} & & \\
\hline 12 & Sinha & 2015 & India & Retrospective & \multicolumn{2}{|c|}{ RTX } & & 93 & & & & \\
\hline 13 & Ravani & 2015 & Italy & RCT & RTX prednisone & Prednisone & 15 & 15 & Case $=6.96$ & Control=6.96 & $11(73 \%)$ & $10(67 \%)$ \\
\hline 14 & Basu, B. & 2015 & India & Retrospective & RTX & MMF & & 24 & & 8 & & \\
\hline 15 & Sun, L. & 2014 & China & Case series & & & & 12 & & & & \\
\hline 16 & Sato, M. & 2014 & Japan & Retrospective & & & & 30 & & & & \\
\hline 18 & Kamei & 2014 & Japan & Case series & & & & 10 & & & & \\
\hline 19 & lijima & 2014 & Japan & RCT & RTX & Placebo & 20 & 23 & Case $=11.5$ & Control=13.6 & 18 (75\%) & $16(67 \%)$ \\
\hline 20 & Tellier, S. & 2013 & France & Retrospective & & & & 18 & & & & \\
\hline
\end{tabular}

NR, Not reported. 
Table 2. Outcome of studies

\begin{tabular}{|c|c|c|c|c|c|c|c|}
\hline Ref. & First author & Type & $\begin{array}{l}\text { Follow-up } \\
\text { Period (month) }\end{array}$ & $\begin{array}{l}\text { Relapse-free } \\
\text { survival }\end{array}$ & $\begin{array}{l}\text { Complete remission } \\
\text { events }\end{array}$ & Side effect & Result \\
\hline 5 & Van Horebeek I & $\begin{array}{l}\mathrm{MCD}=8 \\
\mathrm{FSGS}=1\end{array}$ & 33 & & & & $\begin{array}{l}\text { RTX is effective for treatment of difficult-to-treat SDNS. It reduces the } \\
\text { median yearly number of relapses }\end{array}$ \\
\hline 8 & Suyama K & FSGS & 3 & & 2 & None & $\begin{array}{l}\text { Low-dose cyclosporine RTX is effective in FSGS patients with SRNS. It may } \\
\text { improve the side-effects of Prednisolone and immunosuppressive drugs }\end{array}$ \\
\hline 9 & Kamei K & $\begin{array}{l}\mathrm{MGA}=92 \\
\mathrm{FSGS}=18 \\
\mathrm{DMP}=3\end{array}$ & & & & $\begin{array}{l}\text { Agranulocytosis }=11 \\
\text { Acute infections }=9\end{array}$ & $\begin{array}{l}\text { RTX can be a cause of agranulocytosis in patients with refractory idiopathic } \\
\text { NS }\end{array}$ \\
\hline 11 & Colucci M & & 11.2 & & 14 & & $\begin{array}{l}\text { Assessment of switched memory B cell recovery after RTX may help to } \\
\text { anticipate relapse in patients with nephritic syndrome }\end{array}$ \\
\hline 12 & Chan CY & FSGS & 26.7 & & 12 & & $\begin{array}{l}\text { They diagnosed prognostic markers that describe a subset of patients } \\
\text { with FSGS having an immunologic signature, which represents hypo- } \\
\text { responsiveness to T cell stimulation. RTX is thus more effective. }\end{array}$ \\
\hline 13 & Sinha A & & 12 & & $\begin{array}{l}\text { Sustained remission: } \\
59\end{array}$ & & $\begin{array}{l}\text { RTX is safe and effective in decreasing relapse rates and need for } \\
\text { immunosuppressive drugs in cases with steroid-dependent and calcineurin } \\
\text { inhibitor dependent SRNS }\end{array}$ \\
\hline 14 & Ravani P & & 12 & $\begin{array}{l}\text { Case }=14 \\
\text { Control }=1\end{array}$ & & $\begin{array}{l}\text { Nausea and skin rash were } \\
\text { reported during infusion in } \\
\text { the RTX group; transient acute } \\
\text { arthritis was observed in one case }\end{array}$ & $\begin{array}{l}\text { Three-month proteinuria was } 42 \% \text { less in the RTX group, with no statistical } \\
\text { significance. For the treatment of juvenile SDNS, RTX was non-inferior to } \\
\text { steroids }\end{array}$ \\
\hline
\end{tabular}


$15 \quad$ Basu B

16

17

8

Kamei K

$\mathrm{MCD}=13$

FSGS=11

$M C D=11$

FSGS=2

$M C D=4$

Kimata T

$\mathrm{FSGS}=1$

(n)

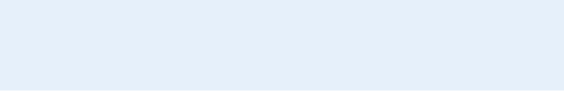

18

\begin{tabular}{|c|c|c|c|c|}
\hline 19 & lijima K & $\begin{array}{l}\mathrm{FSGS}=2 \\
\mathrm{FSGS}=1 \\
\mathrm{MCD}=21 \\
\mathrm{MCD}=23\end{array}$ & 12 & $\begin{array}{l}\text { Case }=6 \\
\text { Control=1 }\end{array}$ \\
\hline
\end{tabular}

20

Tellier S

38.4
Dizziness and mild dyspnea $=1$

Respiratory tract infections $=2$

Mild acute infusion reaction=15

Agranulocytopenia=1

Mild respiratory distress=1

Agranulocytosis $=1$; Severe

pneumonia $=1$; Cough $=4$;

respiratory disturbance $=3$;

hypoxemia $=3$; abdominal

pain $=2$; rash $=2$; wheezing

$=1$; sore throat $=1$; nausea $=1$;

hypertension, $\mathrm{n}=1$

Case $=$ Number of adverse events

357

Infection=23

Infusion reaction $=19$

Control= Number of adverse

events $=251$

Infection=18

Infusion reaction $=13$

Infections=4

Neutropenia $=1$

Flare ups of psoriasis $=1$

Behavioral disorders $=1$
MMF may be a safe and effective maintenance therapy after RTX induction, s an additive immunosuppressant, to maintain remission in children with refractory SRNS

The number of relapses considerably decreased following RTX therapy. It may also improve the growth and obesity indexes in some patients with steroids severe side effects

Following RTX therapy, the frequency of relapses considerably decreased, and the steroid-free period was notably extended.

Repeated RTX in children with SDNS may be an effective therapy option

Additional RTX along with immunosuppressive agents and conventional methylprednisolone is a encouraging treatment

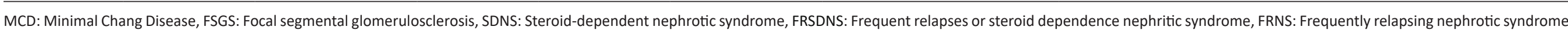
(More than one relapses of nephrotic syndrome within size months following the initial remission, or more than three relapses within any 12-month period), SRNS: Steroid-resistant nephrotic syndrome 
decrease the use of immunosuppressants and steroid. Only one study concluded that RTX might not be effective in all pediatric cases of rapid post-transplant recurrence of NS, and they suggested that before deciding to use this protocol, the ratio of benefit to risk should carefully be balanced on an individual basis (10).

In this systematic review, 17 studied were included, but only two of them were randomized clinical trials (most of them were retrospective studies without control groups), hence we could not do a quantitative synthesis (metaanalysis). In recent year, some review articles have been published on use of RTX in treating childhood NS. The results of a review article regarding efficacy and safety of RTX in treating childhood NS were similar to our results. That study concluded significant gradual benefits for the treatment of NS by adding RTX to corticosteroid and/or calcineurin inhibitors. In safety data they collected, RTX has a limited number of adverse effects; they showed that the most common of them occurred during the infusions, but that study included only randomized control trials and is thus different from our study (1). In our investigation, some studies such as (19) clearly explained the side effects of RTX (19). Another meta-analysis study showed that for childhood refractory NS, RTX might be a promising treatment (3). They showed that RTX also made a higher rate of complete remission, and reduced the proteinuria in patients, but they expressed that the long-time effects and cost-effectiveness of RTX treatment were not fully determined. They suggested additional studies to address these issues (3). They included only four studies in their meta-analysis. One of their studied sources was done only in adults (contrary to our studies) in which the authors systematically summarized and analyzed data from preexisting studies reporting the outcome of RTX (RTX) treatment in relapsing minimal change disease (MCD) and focal segmental glomerulosclerosis (FSGS). They concluded that in frequently relapsing and SDNS due to MCD and FSGS, RTX is effective in reducing the proportion of relapses and sparing immunosuppression. They showed that during treatment with RTX, proteinuria decreased from $2.43(0-15) \mathrm{g} / \mathrm{d}$ to $0(0-4.89) \mathrm{g} / \mathrm{d}(P<$ $0.001)$, while serum albumin increased from 2.9 (1.2-4.6) at baseline to $4.0(1.8-5.09) \mathrm{g} / \mathrm{L}(P=0.001)$, but in most of children studies we reviewed, similar data had not been reported. In the review article of (21), the authors suggested confirmation of their finding by further controlled and prospective studies (21).

\section{Conclusion}

Acknowledging the limitations of this study due to the size and nature of the references included, our systematic review shows that RTX has been effective in the treatment of refractory NS in children, and it could reduce the use of steroid and immunosuppressants. However, further large randomized trials are suggested.

Authors' contribution

AA, YR, HMM, SBA, SN, ME and MRK were involved in drafting the manuscript and revising it critically for important intellectual content. MF revised the manuscript critically for important intellectual content. All authors read and signed the final manuscript.

\section{Conflicts of interest}

The authors declare no conflict of interest.

\section{Ethical considerations}

Ethical issues (including plagiarism, data fabrication, double publication) have been completely observed by the authors.

\section{Funding/Support}

None.

\section{References}

1. Maratea D, Bettio M, Corti MG, Montini G, Venturini F. The efficacy and safety of rituximab in treating childhood nephrotic syndrome: An Italian perspective. Ital J Pediatr. 2016;42:63. doi: 10.1186/s13052-016-0271-6.

2. Madanchi N, Bitzan $M$, Takano $T$. Rituximab in Minimal Change Disease: Mechanisms of Action and Hypotheses for Future Studies. Can J Kidney Health Dis. 2017;4:2054358117698667 doi: 10.1177/2054358117698667.

3. Zhao ZH, Liao GX, Li YQ, Zhou SL, Zou HQ. The efficacy and safety of rituximab in treating childhood refractory nephrotic syndrome: A meta-analysis. Sci Rep. 2015;5:8219. doi: $10.1038 /$ srep08219.

4. Sun L, Xu H, Shen Q, Cao Q, Rao J, Liu HM, et al. Efficacy of rituximab therapy in children with refractory nephrotic syndrome: A prospective observational study in Shanghai. World J Pediatr. 2014;10:59-63. doi: 10.1007/s12519-0140453-5.

5. Van Horebeek I, Knops N, Van Dyck M, Levtchenko E, Mekahli D. Rituximab in children with steroid-dependent nephrotic syndrome: experience of a tertiary center and review of the literature. Acta Clin Belg. 2017;72:147-155. doi: 10.1080/17843286.2016.1208955.

6. Webb H, Jaureguiberry G, Dufek S, Tullus K, Bockenhauer D. Cyclophosphamide and rituximab in frequently relapsing/ steroid-dependent nephrotic syndrome. Pediatr Nephrol. 2016;31:589-94. doi: 10.1007/s00467-015-3245-9.

7. Niu XL, Hao S, Wang P, Zhang W, Guo GM, Wu Y, et al. Single dose of rituximab in children with steroid-dependent minimal change nephrotic syndrome. Biomed Rep. 2016;5:237-242. doi: 10.3892/br.2016.711.

8. Suyama K, Kawasaki Y, Miyazaki K, Kanno S, Ono A, Suzuki Y, et al. Rituximab and low-dose cyclosporine combination therapy for steroid-resistant focal segmental glomerulosclerosis. Pediatr Int. 2016;58:219-23. doi: 10.1111/ ped.12804.

9. Kamei K, Ogura M, Sato M, Sako M, Iijima K, Ito S. Risk factors for relapse and long-term outcome in steroiddependent nephrotic syndrome treated with rituximab. Pediatr Nephrol. 2016;31:89-95. doi: 10.1007/s00467-0153197-0.

10. Grenda R, Jarmużek W, Rubik J, Piątosa B, Prokurat S. Rituximab is not a "magic drug" in post-transplant recurrence of nephrotic syndrome. Eur J Pediatr. 2016;175:1133-1137. doi: 10.1007/s00431-016-2747-1.

11. Colucci M, Carsetti R, Cascioli S, Casiraghi F, Perna A, Rava 
L, et al. B Cell Reconstitution after Rituximab Treatment in Idiopathic Nephrotic Syndrome. J Am Soc Nephrol. 2016;27:1811-22. doi: 10.1681/ASN.2015050523.

12. Chan CY, Liu ID, Resontoc LP, Ng KH, Chan YH, Lau PYW, et al. T Lymphocyte Activation Markers as Predictors of Responsiveness to Rituximab among Patients with FSGS. Clin J Am Soc Nephrol. 2016;11:1360-8. doi: 10.2215/ CJN.11941115.

13. Sinha A, Bhatia D, Gulati A, Rawat M, Dinda AK, Hari P, et al. Efficacy and safety of rituximab in children with difficultto-treat nephrotic syndrome. Nephrol Dial Transplant. 2015;30:96-106. doi: 10.1093/ndt/gfu267.

14. Ravani P, Rossi R, Bonanni A, Quinn RR, Sica F, Bodria $M$, et al. Rituximab in Children with Steroid-Dependent Nephrotic Syndrome: A Multicenter, Open-Label, Noninferiority, Randomized Controlled Trial. J Am Soc Nephrol. 2015;26:2259-66. doi: 10.1681/ASN.2014080799.

15. Basu B, Mahapatra TKS, Mondal N. Mycophenolate mofetil following rituximab in children with steroid-resistant nephrotic syndrome. Pediatrics. 2015;136:e132-9. doi: 10.1542/peds.2015-0486.

16. Sato $M$, Ito $S$, Ogura $M$, Kamei $K$. Impact of rituximab on height and weight in children with refractory steroiddependent nephrotic syndrome. Pediatr Nephrol. 2014;29:1373-9. doi: 10.1007/s00467-014-2792-9.
17. Kimata T, Hasui M, Kino J, Kitao T, Yamanouchi S, Tsuji S, et al. Novel use of rituximab for steroid-dependent nephrotic syndrome in children. Am J Nephrol. 2013;38:483-8. doi: $10.1159 / 000356439$.

18. Kamei K, Okada M, Sato M, Fujimaru T, Ogura M, Nakayama M, et al. Rituximab treatment combined with methylprednisolone pulse therapy and immunosuppressants for childhood steroid-resistant nephrotic syndrome. Pediatr Nephrol. 2014;29:1181-7. doi: 10.1007/s00467-014-2765-z.

19. Iijima K, Sako M, Nozu K, Mori R, Tuchida N, Kamei $\mathrm{K}$, et al. Rituximab for childhood-onset, complicated, frequently relapsing nephrotic syndrome or steroiddependent nephrotic syndrome: a multicentre, double-blind, randomised, placebo-controlled trial. Lancet. 2014;384:127381. doi: 10.1016/S0140-6736(14)60541-9.

20. Tellier S, Brochard K, Garnier A, Bandin F, Llanas B, Guigonis V, et al. Long-term outcome of children treated with rituximab for idiopathic nephrotic syndrome. Pediatr Nephrol. 2013;28:911-8. doi: 10.1007/s00467-012-2406-3.

21. Kronbichler A, Kerschbaum J, Fernandez-Fresnedo G, Hoxha E, Kurschat CE, Busch M, et al. Rituximab treatment for relapsing minimal change disease and focal segmental glomerulosclerosis: A systematic review. Am J Nephrol. 2014;39:322-30. doi: 10.1159/000360908.

Copyright $\odot 2018$ The Author(s); Published by Nickan Research Institute. This is an open-access article distributed under the terms of the Creative Commons Attribution License (http://creativecommons.org/licenses/by/4.0), which permits unrestricted use, distribution, and reproduction in any medium, provided the original work is properly cited. 